\title{
Search for Borrelia sp. in Ticks Collected from Potential Reservoirs in an Urban Forest Reserve in the State of Mato Grosso do Sul, Brazil: a Short Report

\author{
IP da Costa/ ${ }^{+}$, VLN Bonoldi*, NH Yoshinari*
}

Departamento de Clínica Médica, Centro de Ciências Biológicas, Universidade Federal de Mato Grosso do Sul, Caixa Postal 549, 79070-900 Campo Grande, MS, Brasil *Laboratório de Interação Microorganismo e Artrite, Departamento de Clínica Médica,

Faculdade de Medicina, Universidade de São Paulo, São Paulo, SP, Brasil

A total of 128 ticks of the genus Amblyomma were recovered from 5 marsupials (Didelphis albiventris) - with 4 recaptures - and 17 rodents (16 Bolomys lasiurus and 1 Rattus norvegicus) captured in an urban forest reserve in Campo Grande, State of Mato Grosso do Sul, Brazil. Of the ticks collected, 95 (78.9\%) were in larval form and 22 (21.1\%) were nymphs; the only adult (0.8\%) was identified as A. cajennense. Viewed under dark-field microscopy in the fourth month after seeding, 9 cultures prepared from spleens and livers of the rodents, blood of the marsupials, and macerates of Amblyomma sp. nymphs revealed spiral-shaped, spirochete-like structures resembling those of Borrelia sp. Some of them showed little motility, while others were non-motile. No such structures could be found either in positive Giemsa-stained culture smears or under electron microscopy. No PCR amplification of DNA from those cultures could be obtained by employing Leptospira sp., B. burgdorferi, and Borrelia sp. primers. These aspects suggest that the spirochete-like structures found in this study do not fit into the genera Borrelia or Leptospira, requiring instead to be isolated for proper identification.

Key words: Borrelia sensu lato vectors - Borrelia sp. reservoirs - borreliosis-like illness - Mato Grosso do Sul - Brazil

Spirochetes of the genus Borrelia sensu lato are etiological agents of Lyme disease, which is transmitted to humans and to domestic and wild animals primarily through bites of ticks of the genus Ixodes.

This borreliosis can be caused by a number of species of worldwide distribution, such as B. burgdorferi sensu stricto, found in the United States and Europe; B. garinii and B. afzelii, in Europe; and B. japonica, in Asia (Felfsenfeld 1965, Steere et al. 1977, Barbour 1984, Baranton et al. 1992). In addition to these species isolated from Ixodes sp. ticks, another spirochete, named $B$. lonestari, found in the United States and isolated from Amblyomma americanum (Barbour et al. 1996), has been implicated in causing cutaneous lesions similar to those of Lyme disease.

In 1951, Prof. Henrique de B Aragão, of Instituto Oswaldo Cruz, Rio de Janeiro, Brazil, sent to Dr Gordon E Davis, in the United States (Davis 1952), 31 specimens of Ornithodoros brasiliense for analysis, which had been collected by Prof. Raul di Primo in the State of Rio Grande do Sul. After eliciting nymphs of this argasid tick to feed on mice hosts, Prof. Aragão was able to recover spirochetes from their blood, naming them $B$. brasiliensis. The few references available on this matter fail to provide any information on the biology or etiological role of this pathogen, other than mentioning that it is morphologi-

This work was supported by Capes/PICD/FUFMS/Fapesp. ${ }^{+}$Corresponding author. Fax: +55-67-345.3203. E-mail: izapec@uol.com.br

Received 31 August 2001

Accepted 22 April 2002 cally hard to distinguish from other spirochetes.

More recently, ticks of the species A. cajennense, A. aureolatum, Ixodes sp., I. didelphidis, and I. loricatus have been identified (Barros-Battesti 1998, Costa 1998, Abel et al. 2000) in rodents and marsupials contaminated with spirochetes morphologically similar to those of the genus Borrelia.

Laboratorial techniques for diagnosis have been developed and diagnostic criteria established, thus allowing an improved knowledge on this borreliosis in Brazil, with the identification of patients showing clinical manifestations that are similar, if not identical, to those of Lyme disease and presenting serological cross-reactivity against Borrelia sensu lato antigens (Yoshinari et al. 1992a,b, 1993a,b, 1997, Joppert 1995, Ishikawa 1996, Costa et al. 1996, Pirana et al. 1996).

The name Lyme disease-like illness, to designate an emerging zoonosis found in Brazil, was proposed by Yoshinari et al. (1999, 2000), based on clinical similarities with the classical Lyme disease described by Dr Allen C Steere in 1977, although with some laboratorial differences. Brazilian patients' sera react differently to $B$. burgdorferi antigens, and, despite many attempts, no etiological agent has been cultured so far, suggesting that this is not a single disease, but rather a complex clinical syndrome.

The present study was carried out in order to verify the possible presence of Borrelia sensu lato in ticks found as ectoparasites of marsupials and rodents in an urban forest reserve of Campo Grande, the capital city of the State of Mato Grosso do Sul, in southwestern Brazil.

\section{MATERIALS AND METHODS}

Study area - The 48.5-hectare area selected, known as Reserva Biológica, is located in the campus of Universidade Federal de Mato Grosso do Sul at Campo 
Grande. This reserve borders residential neighborhoods and has a lake that nearly divides its extension into two sectors exhibiting distinct vegetations - while one of them has high-growing grass and Cerrado trees, the other has features of palm swamp and gallery forest.

This location was chosen because two patients out of a total of 15 in Campo Grande with clinical features and laboratorial diagnosis compatible with Lyme disease-like illness had frequented it (Costa 1998).

Capture of animals - Capture was performed for three weeks in a row, for five consecutive days a week, in July 1997. Weather conditions were recorded during this period.

The live traps employed were baited with bacon slices for marsupials and corn grains for rodents. Traps were inspected daily, and the animals captured were anesthesized with sulfuric ether in plastic bags for further processing.

Processing of mammals - Once anesthesized, mammals were identified, weighed, and measured. They were combed over a white tray to recover their ectoparasites. Ectoparasites adhering to the skin were removed with the help of tweezers.

Blood was drawn from the caudal vein of the marsupials. Part of the sample was seeded in BSK culture medium and another portion was used for preparing Giemsastained smears. Serum separated from the remaining blood was frozen at $-20^{\circ} \mathrm{C}$ for further studies. The initials MSM plus a sequential number were shaved on the marsupials, which were then released into their original environment, thus becoming available for recapturing.

The rodents captured were initially kept under observation for the presence of ticks during one week, at the end of which they were anesthesized and submitted to cardiac puncture. A few drops of blood were inoculated into BSK medium, and some more were used for preparing Giemsa-stained smears for optical microscopy. Following sacrifice, liver and spleen samples were seeded in BSK culture medium. The initials MSR plus a sequential number were shaved on the animals, which were then weighed, measured, and frozen at $-20^{\circ} \mathrm{C}$ until taxidermy time. Following taxidermy, they were deposited at the mastozoology collection (Dr Michel Miretzki) of Museu de História Natural Capão da Imbuia, Departmento de Zoologia, of the municipality of Curitiba, State of Paraná.

Processing of ticks - All ectoparasites found were taxonomically identified at the Laboratório de Artrópodes, Instituto Butantan, São Paulo (Dr Darcy Morais BarrosBattesti, July 1997). Unprocessed specimens were deposited at its acarology collection.

Upon being washed in ethanol, ticks were macerated and seeded in BSK culture medium under sterile conditions and laminar flow in the Laboratório de Investigação em Reumatologia (LIM-17), Faculdade de Medicina, Universidade de São Paulo, where the cultures were followed up for spirochetes' growth.

Analysis of culture media - Cultures were kept in anaerobic conditions in an incubator at $33^{\circ} \mathrm{C}$. Aliquots were periodically viewed under a dark-field microscope with immersion lens. Spirochete-like positive cultures were reinoculated in BSK.
Analysis of spirochetes - Spirochetes were searched for in different ways: by direct examination of cultures under a dark-field microscope with immersion lens; in Giemsa-stained blood smears; and by electron microscopy (Instituto Adolfo Lutz and Departamento de Anatomia Patológica, Faculdade de Medicina, Universidade de São Paulo).

Cultures exhibiting spiral-shaped structures were submitted to PCR in order to allow differentiation from structures of the genus Leptospira, and to detect the presence of Borrelia sp. DNA.

DNA extraction and amplification - DNA was extracted according to the protocol described by Sambrook et al. (1989), with minor modifications.

For the analysis of the amplification products, electrophoresis in $2.5 \%$ agarose gel and ethydium-bromide staining were employed (Sambrook et al. 1989).

In order to differentiate from Leptospira sp. those spirochetes found in the mammals and ticks, a positive control was employed consisting of the species $L$. interrogans, of serogroup Tarassovi (Laboratório de Zoonoses Bacterianas, Departamento de Medicina Veterinária Preventiva e Saúde Animal, Faculdade de Medicina Veterinária e Zootecnia, Universidade de São Paulo, FMUSP).

For negative control, a microtube was used, containing ultrafiltered water with a standard of 100-Bp molecular weight (Pharmacia Biotech, Uppsala, Sweden).

The DNA of Borrelia sensu lato was detected through PCR with the use of primers of flagellin and 16S rRNA, as described by Barbour et al. (1996), a procedure capable of identifying microorganisms of the genus Borrelia.

The positive control consisted of DNA extracted from three Borrelia species (B. burgdorferi, B. afzelli, and B. garinii) kept under culture at Laboratório de Investigação em Reumatologia, FMUSP. A standard of known molecular weight was used for reference.

\section{RESULTS}

Weather conditions - The highest and lowest temperatures recorded in the study area during the period of capture were $15.2^{\circ} \mathrm{C}$ and $30.9^{\circ} \mathrm{C}$, with a mean of $21.04^{\circ} \mathrm{C}$.

Identification of the mammals captured - Five marsupials of the species Didelphis albiventris were collected ( 3 males and 2 females), with 4 recaptures. Of the 17 rodents collected, 16 were identified as Bolomys lasiurus and 1 as Rattus norvegicus.

Identification of ectoparasites - A hundred and eighteen ticks were recovered from the marsupials, 117 of which belonged to the genus Amblyomma. Of those, 95 (81.2\%) were in the larval stage and $22(18.8 \%)$ were nymphs; the only adult found $(0.8 \%)$ was identified as A. cajennense.

From the rodents of the species B. lasiurus, 11 specimens of Amblyomma sp. were collected, 6 (54.5\%) of which were larvae and 5 (45.5\%) nymphs.

Analysis of culture media under dark-field microscopy - Spiral-shaped structures, most of them with little motility, were found in nine cultures, although only in the fourth month after inoculation. In addition, the structures were sometimes seen tangled, in the manner of Borrelia sp. cultures (Figure). 
Of the positive cultures, 4 were prepared from rodent spleens, 1 from rodent liver, 1 from marsupial blood, and 3 from macerates of Amblyomma sp. nymphs.

No structures suggestive of spirochetes, however, were observed in Giemsa-stained aliquots obtained from culture media, or in at least 2 analyses performed under electron microscopy.

\section{DISCUSSION}

The weather conditions at the time of capture must be taken into account, as the development stages of ticks correlate with the seasons (Flechtmann 1973, BarrosBattesti 1998).

Barros-Battesti (1998), in an extensive study carried out in the municipality of Itapevi, State of São Paulo, found the highest frequency of rodents, along with the highest numbers of immature ticks, to be related to the dry and cold season, which lasts from April to September.

In the present study, capture was performed in July, when rainfall was entirely absent, with a mean temperature of $21.04^{\circ} \mathrm{C}-$ i.e., a typical dry and cold winter month, in terms of the region's pattern. A total of 5 marsupials (D. albiventris) and 17 rodents (16 of the species $B$. lasiurus and 1 of $R$. norvegicus) were collected during that period, providing 227 immature forms (larvae and nymphs) of Amblyomma sp., along with one adult form of the same genus. On the other hand, in the study carried out by Barros-Battesti in Itapevi, adult ticks were predominant in the rainy and warm season (October to March).

All tick nymphs and larvae identified in the present work belonged to the genus Amblyomma, with one adult specimen identified as A. cajennense; the remaining ectoparasites captured did not belong to the sub-order Ixodidae.
A. cajennense, popularly known as "star-tick" (Flechtmann 1975), is widely distributed in the Americas, particularly in warmer regions. It can be found on wild and domestic birds alike, as well as on mammals and, not rarely, on ophidians.

Humans are often bitten by this tick in any of its development stages, but mainly as larvae and nymphs. Found in large numbers on fields and pastureland in dry and cold seasons, it is regarded as the vector of spotted fever group rickettsiosis and equine babesiosis.

The identification of A. americanum as the vector, in the United States, of a distinct, uncultivable species of Borrelia known as B. lonestari (Barbour et al. 1996), recognized as the etiological agent of a Lyme disease-like illness causing cutaneous lesions without systemic manifestations, has caused the inclusion of the genus Amblyomma to the list of known vectors of this disease to humans.

The investigations performed by Barros-Battesti et al. $(1998,2000)$ and Yoshinari et al. (1997) in the municipality of Cotia, State of São Paulo, led to the recovery, from rodents and marsupials, of tick species other than $A$. cajennense, such as I. didelphidis, I. loricatus, A. aureolatum and Rhipicephalus sanguineus; all of which, except for the last one, were often found contaminated with spirochete-like structures similar to those immobile structures found in Campo Grande.

Perhaps because the study in Campo Grande has spanned only a short period of the year and has covered a limited stretch of land, no occurrence could be detected of tick species other than those four mentioned above a finding that, nonetheless, corroborates results of previous investigations showing an absence of records of

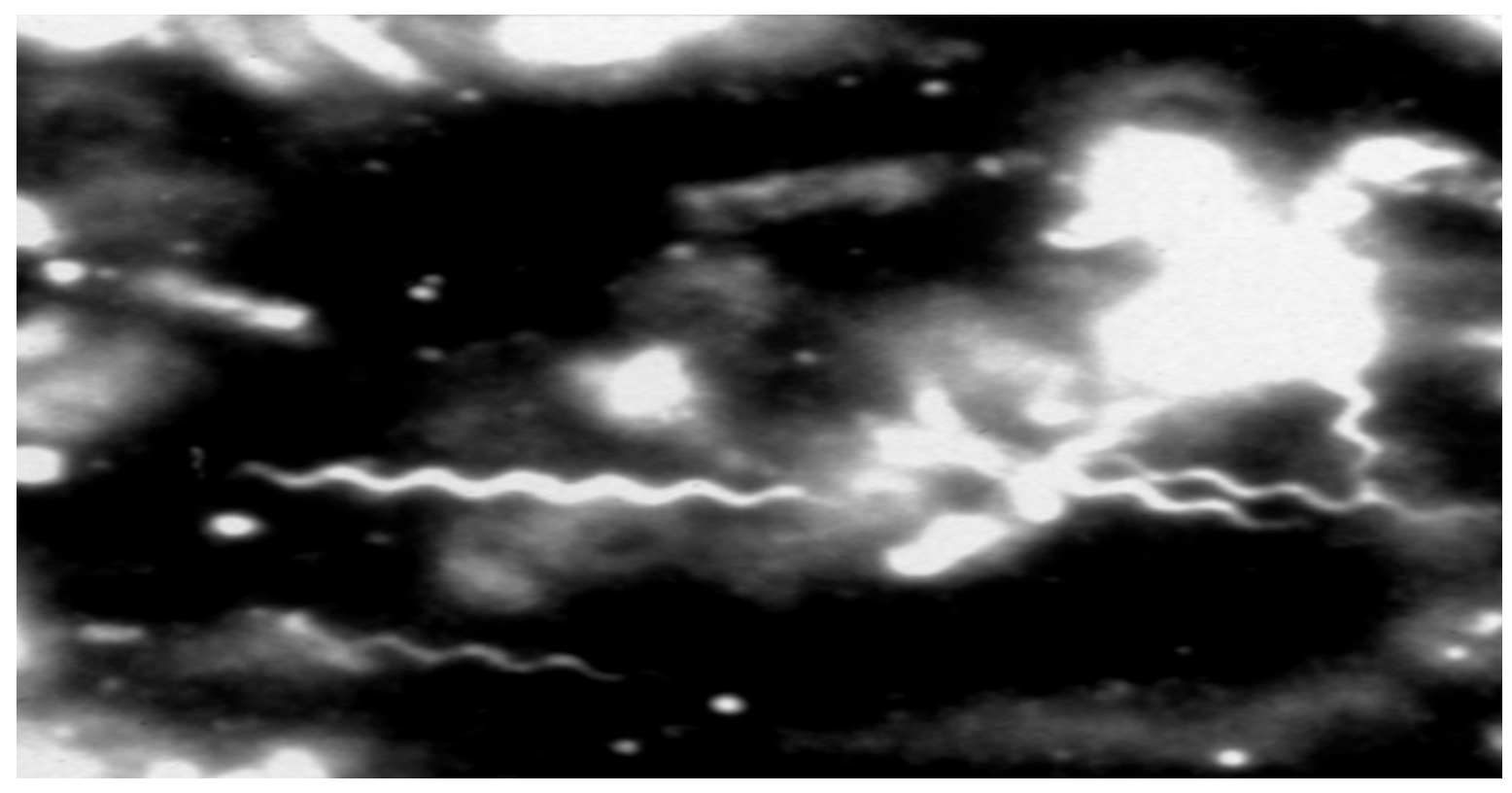

Spirochete-like structures seen under dark-field microscopy in BSK culture of spleen of rodent (Bolomys lasiurus) captured in the Biological Reserve of Universidade Federal de Mato Grosso do Sul (Campo Grande, State of Mato Grosso do Sul, Brazil). 
Ixodes sp. ticks in this region of the country. This constitutes a very relevant epidemiological finding, since the transmission of the disease in Brazil might be linked to the presence of Amblyomma sp. vectors.

Additionally, the possible involvement of Amblyomma sp. in the transmission of this Lyme disease-like illness in Brazil is supported by reports of human cases related to casual bites of this arthropod genus in the State of Rio de Janeiro (Yoshinari et al. 1999, 2000).

It is possible to suggest that ticks of the I. ricinus complex are the vectors responsible for the transmission of microorganisms that cause classical Lyme disease in the United States and Europe, while others, such as Amblyomma sp., would be implicated in the appearance of a similar disease. Curiously, cases of Lyme disease have been reported in Australia (Russell et al. 1994), although neither vectors nor microorganisms have been identified yet.

Abel et al. (2000) found immobile Borrelia-like structures in cultures from ticks and small mammals collected in Cotia, and some of these isolates were recognized through indirect immunofluorescence using sera of patients with Lyme disease-like illness, suggesting that these structures could be implicated in the etiology of this disease in Brazil.

On the other hand, Schonberg et al. (1992) described immobile spiral microorganisms obtained from skin and cerebrospinal fluid cultures from patients with Lyme borreliosis. Later (1994), however, the authors discovered by electron microscopy that such structures were in fact flagella of microorganisms contaminating the culture medium.

In the present study, the finding of spiral-shaped structures in cultures from blood of marsupials and organs of rodents, as well as from macerates of the ticks, is in agreement with results obtained by Abel et al. (2000). It is important, however, to point out that similar structures have appeared in blood and cerebrospinal fluid cultures from patients with Lyme disease-like illness (Yoshinari et al. 1999).

The negative results of PCR amplification (employing Leptospira sp. or Borrelia sp. primers) of DNA from cultures containing spirochete-like structures from ticks and mammals, and also from blood samples of clinical patients (Costa 1998, Barros 2000), strongly suggest that the causative agent of the disease in Brazil should be quite different from any already known borrelias.

The first cases of the disease in Brazil were discovered in Cotia (Yoshinari et al. 1992a,b), and clinical features, especially the presence of erythema migrans, have been the leading criteria for diagnosis. Epidemiological data such as tick-bite history, contact with domestic animals, and attendance at risk areas are helpful information. Positive serology for B. burgdorferi has been obligatory, but because the etiological agent seems to be a novel one, serological assays have displayed low sensitivity. Often, ELISA assays reveal low antibody titers and the Western Blotting pattern of reactivity differs from that observed in sera of North American patients. Finally, spirochete-like microorganisms, although seen in peripheral blood and cerebrospinal fluid of patients, are uncultivable when added into BSK medium (Yoshinari et al. 1997, 1999, 2000).

Because of these microbiological and serological differences and the impossibility of amplifying DNA from primers of $B$. burgdorferi flagellin, in addition to the fact that the spirochete-like microorganisms do not belong to the genus Leptospira, the existence can be postulated of a new clinical syndrome called Lyme disease-like illness, whose causative agent is either a very different borrelia or a microorganism of another genus transmitted by ticks other than those of the I. riccinus complex.

Further studies shall lead to the isolation and characterization of this etiological agent, thus permitting a more accurate diagnosis of this emerging zoonosis in Brazil, which has been met with increased interest in many medical specialities, as this challenging infectious syndrome has been affecting more and more patients over time.

\section{ACKNOWLEDGMENTS}

To Dr M Miretzki, for the taxonomic identification of the small rodents; to SA Vasconcelos, MB Heinemann, and A Cortez for the PCR procedures for Lesptospira sp.; to Dr PJ Barros for the help provided during the PCR procedures for Borrelia burgdorferi sensu lato; to Dr DB Batesti for the taxonomic classification of the ectoparasites; and to biologist IS Abel for collaboration in the collection and processing of the wild animals and ectoparasites.

\section{REFERENCES}

Abel IS, Marzagão G, Yoshinari NH, Schumaker TTS 2000. Borrelia-like spirochetes recovered from ticks and small mammals collected in the Atlantic Forest Reserve, Cotia county, state of São Paulo, Brazil. Mem Inst Oswaldo Cruz 95: 621-624.

Baranton G, Postic D, Saint Giros I 1992. Delineation of Borrelia burgdorferi sensu stricto, Borrelia garinii sp. nov. and VS 461 associated with Lyme borreliosis. Inst J Sys Bacteriol 42: 378-383.

Barbour AG 1984. Isolation and cultivation of Lyme disease spirochetes. Yale J Biol Med 57: 521.

Barbour AG, Maupin GO, Teltow GJ, Carter CJ, Piesman J 1996. Identification of an uncultivable Borrelia species in the hard tick Amblyomma americanum: possible agent of a Lyme disease-like illness. J Infect Dis 173: 403-409.

Barros-Battesti DM 1998. Estudo de Carrapatos e Pequenos Mamíferos Silvestres Naturalmente Infectados com Espiroquetas Semelhantes a Borrelia, no Município de Itapevi, Estado de São Paulo, PhD Thesis, Faculdade de Saúde Pública, Universidade de São Paulo, São Paulo,142 pp.

Barros-Battesti DM, Yoshinari NH, Bonoldi VLN, Gomes AC 2000. Parasitism by Ixodes didelphidis and I. loricatus (Acari: Ixodidae) on small wild animals from the Atlantic Forest in State of São Paulo, Brazil. J Med Entomol 37: 820-827.

Barros PJL 2000. Caracterização Clínica e Laboratorial da Doença de Lyme no Brasil, Através de Métodos Imunológicos e Reação em Cadeia de Polimerase, PhD Thesis, Faculdade de Medicina, Universidade de São Paulo, São Paulo, 163 pp.

Burgdorfer W 1993. Discovery of Borrelia burgdorferi. In PK Coyle, Lyme Disease, Mosby Year Book, St. Louis, Missouri, p. 3.

Costa IP 1998. Pesquisa de Anticorpos Anti Borrelia e do Agente Etiológico em Soro e Líquor de Pacientes com Manifestações Clínicas Compatíveis com a Doença de Lyme, no Estado de 
Mato Grosso do Sul, PhD Thesis, Faculdade de Medicina, Universidade de São Paulo, São Paulo, 125 pp.

Costa IP, Yoshinari NH, Barros PJL, Bonoldi VLN, Leon EP, Zeitune AD, Cossermelli W 1996. Doença de Lyme em Mato Grosso do Sul: relato de três casos, incluindo o primeiro relato de meningite de Lyme no Brasil. Rev Hosp Clin Fac Med S Paulo 51: 253-257.

Davis GE 1952. Observations on the biology of the Argasid tick Ornithodoros brasiliensis Aragão, 1923, with the recovery of a spirochete, Borrelia brasiliensis, n. sp. Parasitology 38: 473-476.

Felfsenfeld O 1965. Borreliae, human relapsing fever, and parasite-vector-host relationships. Bacteriol Rev 29: 46-74.

Flechtmann CHW 1973. Ácaros Metastigmata ou Ixodides "carrapatos". In Ácaros de Importância Médico-veterinária, Nobel, São Paulo, p. 45-104.

Ishikawa MM 1996. Epidemiologia da Borreliose de Lyme em Bovinos na Região Sudeste do Brasil e Padronização do Diagnóstico Sorológico, MSc Thesis, Instituto de Biologia, Universidade Federal Rural do Rio de Janeiro, Seropédica, $51 \mathrm{pp}$.

Joppert AM 1995. Estudo Soro-epidemiológico da Infecção por Borrelia burgdorferi em Cães da Região de Cotia, São Paulo, MSc Thesis, Faculdade de Medicina Veterinária e Zootecnia, Universidade de São Paulo, São Paulo. 83 pp.

Pirana S, Bento RF, Bogar P, Silveira JAM, Yoshinari NH 1996. Paralisia facial e surdez súbita bilateral na doença de Lyme. Rev Bras Otorrinol 62: 500-502.

Russell RC, Doggett S, Munro R, Ellis J, Avery D, Hunt C, Dickeson D 1994. Lyme disease: a search for a causative agent in ticks in south-eastern Australia. Epidemiol Infect 112: 375-384.

Sambrook J, Fritsh EF, Maniatis T 1989. Molecular Cloning: $a$ Laboratory Manual, Cold Spring Harbor Press, New York, 957pp.

Schonberg A, Kashohrer A, Brem Srath PM 1994. Further im- portant details about immobile spiral microorganismis in skin biopsies and cerebrospinal fluid from patients with Lyme borreliosis. In 6th International Conference on Lyme Borreliosis, Bologna, Italy, June, Abstracts.

Schonberg A, Kashohrer A, Ott A, Rath PM, Diesterweg I, Buslau M 1992. Immobile spiral microorganisms in skin and cerebrospinal fluid biopsies from patients with Lyme borreliosis. In 5th International Conference on Lyme Borreliosis, Virginia, Abstracts.

Steere AC, Malawista SE, Snydman DR, Shope RE, Andiman WA, Ross MP, Steele FM 1977. Lyme arthritis: an epidemic of oligoarticular arthritris in children and adults in three Connecticut communities. Arthritis Rheum 20: 7-17.

Yoshinari NH, Barros PJL, Bonoldi VLN 1997. Perfil da Borreliose de Lyme no Brasil. Rev Hosp Clin Fac Med S Paulo 52: 111-117.

Yoshinari NH, Barros PJL, Cruz FCM, Oyafuso LK, Mendonça M, Baggio D, Yassuda P, Cossermelli W 1992a. Clínica e sorologia da doença de Lyme no Brasil. Rev Bras Rheumatol 32(Supl. 4): 57-63.

Yoshinari NH, Barros-Battesti PJL, Gauditano G, Fonseca AH 2000. Report of 57 cases of Lyme-like disease (LLD) in Brazil. Arthritis Rheum 43: S188.

Yoshinari NH, Bonoldi VLN, Barros-Battesti DM, Schumacker TTS 1999. Doença de Lyme-símile no Brasil. Rev Bras Reumatol 39: 57-58.

Yoshinari NH, Barros PJL, Yassuda P, Baggio D, Steere AC 1992b. Estudo epidemiológico da doença de Lyme no Brasil. Rev Hosp Clin Fac Med S Paulo 47: 71-75.

Yoshinari NH, Oyafuso LK, Monteiro FGV, Barros PJL 1993a. Doença de Lyme: relato de um caso observado no Brasil. Rev Hosp Clin Fac Med S Paulo 48: 170-174.

Yoshinari NH, Steere AC, Barros PJL, Cruz FCM, Mendonça M, Oyafuso LK, Levy L, Cossermelli W 1993b. Lyme disease in Brazil: report of five cases. Rev Esp Reumatol 20 (Supl. 1): 156. 
636 Search for Borrelia sp. in Brazil - IP da Costa et al. 